\title{
Estrategias de supervivencia de las lesbianas en el mercado laboral en Aguascalientes, México
}

\author{
Lesbians' Survival Strategies in the Labor Market of Aguascalientes, \\ Mexico \\ Estrategias de Sobrevivência de Lésbicas no Mercado Laboral em
Aguascalientes, México
}

Grecia Lorena Valencia Arcos

Universidad Autónoma de Aguascalientes, México

lorena_grecia@hotmail.com

María de Jesús Ávila Sánchez

Universidad Autónoma de Nuevo León, México

marycolef@yahoo.com

\section{Resumen}

La división sexual del trabajo representa un obstáculo para el desarrollo profesional de las mujeres y las lesbianas es doblemente difícil comprar, quedarse o volver a entrar en un espacio de trabajo. Por método de triangulación de datos cuantitativos y cualitativos, los resultados muestran que tanto el sexo femenino, lesbianas masculinas y andróginas tienen la necesidad de ocultar su sexualidad y heteronormatizar sus cuerpos, lo que llevó a tener que ocultar sus vidas en el trabajo, e incluso tener que construir realidades ficticias para integrar la dinámica social de las diferentes áreas de trabajo en las que están inseridas.

Palabras-Chave: Lesbiana; Corporeidad; La Exclusión del Mercado de Trabajo; La Discriminación.

\begin{abstract}
The sexual division of labor is an obstacle for the professional development of women, but for lesbian women, both to enter and to take hold in the labor market is doubly difficult. By means of a triangulation of both quantitative and qualitative data, we obtained results that show that lesbians, whether female, masculine or androgynous, have the need to hide their sexuality and their heteronormalized bodies, which frequently led them to hide their lives at work, and even to build fictitious realities, in order to integrate themselves into the social dynamics of the different areas of work in which they operate.
\end{abstract}

Keywords: Lesbian; Corporeality; Exclusion from the Labor Market; Discrimination.

\section{Resumo}

A divisão sexual do trabalho representa um obstáculo para o desenvolvimento profissional das mulheres e lésbicas, é duplamente difícil comprar, ficar ou re-introduzir um espaço de trabalho. Pelo método de triangulação de dados quantitativos e qualitativos, os resultados mostram que tanto do sexo feminino, lésbicas masculinas e andróginos têm a necessidade de esconder a sua sexualidade e seus corpos heteronormatizar, o que levou a ter que esconder suas vidas no trabalho, e até mesmo ter que construir realidades fictícias para integrar na dinâmica social das diferentes áreas de trabalho em que estão inseridas.

Palavras-Clave: Lésbica; Corporeidade; Exclusão do Mercado de Trabalho; Discriminação. 


\section{Introducción}

El cuerpo, la corporalidad y el género han sido unos de los temas más estudiados y polémicos en las últimas décadas. $\mathrm{La}$ concepción del cuerpo como un todo, y no como un conjunto de órganos integradores de un sistema (CASTAÑEDA, 2008), ha abierto a los científicos sociales la posibilidad de estudiar el impacto que han tenido las diferentes culturas en la construcción física y psicológica de las y los sujetos influenciados por un sistema sexo-género-sexualidadcuerpo (BUTLER, 2007), mismo que ha sido construido para el correcto funcionamiento del sistema capitalista-patriarcalheteronormativo.

Las lesbianas, mujeres que siente una atracción erótica-emocional-afectiva por otra mujer; han sido y siguen siendo consideradas como pecadoras, delincuentes y en algunos casos como enfermas mentales. Trayendo como consecuencia un alto índice de discriminación, violencia y exclusión, de los espacios públicos y privados, por el hecho de optar por una sexualidad diferente a la heterosexualidad (FIOCCHETTO, 1993).

Las lesbianas al igual que cualquier persona en las diferentes sociedades, tienen que desarrollarse en diversos espacios con el fin de cubrir sus necesidades: alimento, descanso, vestido, educación, trabajo, entre otras. Al igual que la mayoría de las personas que no cumplen con el sistema sexo-génerocuerpo-sexualidad o que sus cuerpos no han sido adaptados a las exigencias del sistema capitalista-patriarcal-heteronormativo; sufren de discriminación $\mathrm{y}$ violencia en las diferentes áreas en las que se relacionan, principalmente en aquellas en las que se compite por un incentivo económico.

El panorama laboral que actualmente vive México, tras la reforma del artículo $3^{\circ}$ constitucional, se enmarca en una constante flexibilización y especialización de la mano de obra, pleno de inseguridades, precarización e informalidad; ante la imposibilidad de contar con empleos fijos y duraderos que con anterioridad se podían adquirir en las grandes empresas $y$ corporaciones nacionales, internacionales $\mathrm{y}$ transnacionales. Tras la industrialización y la división sexual del trabajo, ser mujer, aun en el siglo XXI, representa una limitante para el desarrollo profesional y/o laboral, y si a ello se suma el ser una lesbiana masculina o femenina; resulta doblemente complicado adquirir, permanecer o reinsertarse en el mercado de trabajo.

El objetivo general consiste en describir y explicar las estrategias de supervivencia en el área laboral de las lesbianas masculinas y femeninas, específicamente: 1. Identificar las áreas laborales en las que se insertan con mayor frecuencia las mujeres lesbianas en el año 2010 a nivel nacional; 2. Describir y explicar las condiciones laborales en las cuales se encuentran las lesbianas masculinas $\mathrm{y}$ femeninas a nivel nacional y local; 3 . Conocer la influencia que tienen la masculinización y/o feminización de los cuerpos de las lesbianas en la inserción, permanencia y deserción del ámbito laboral.

\section{Interseccionalidad, Sexo, Cuerpo, Género y Sexualidad}

La interseccionalidad (Figura 1) propuesta desde el pensamiento Negro Feminista desarrollado principalmente por las autoras Ángela Davis, bell hooks y Patricia Hill Collins, consiste en concebir a la o el sujeto como un receptor de diversas conexiones y factores para la construcción de su identidad, cuerpo, sexualidad, género, entre otros (GIL, 2009).

El sistema sexo-género-sexualidad-cuerpo propuesto por Judith Butler (2007) postula que el sexo actúa como la base neutral prediscursiva del género, es decir, la base 
desnaturalizada mediante la cual es posible construir el género, evitando la concepción de este como el resultado de una relación binaria con los sexos, por lo tanto, el sexo se adquiere en el momento en que se verbaliza. No es que se nace con un sexo o un género, sino, que la cultura por medio del lenguaje asigna un sexo y construye un género en referencia al sistema patriarcal. Se debe de tener una congruencia con el sexo-género, y también es imprescindible tener en cuenta el cuerpo y la sexualidad, se debe de ser de un sexo femenino y por género mujer, ser femenina (delgada y blanca) y heterosexual (como única opción), para poder cumplir con las normas sociales para el correcto comportamiento y corporalidad de las y los sujetos, y ser aceptados dentro del sistema heterosexual y patriarcal.

La disidencia de la heterosexualidad en México en los últimos años ha tornado a ser un tema político y polémico, la lucha por derechos y la no discriminación de las personas que optan por una sexualidad no correspondiente a la culturalmente establecida, las ha llevado a tener que crear estrategias para poder sobrevivir e insertarse en diferentes espacios de la sociedad.

La identidad, el cuerpo y las corporalidades se construyen a partir del contexto cultural en el cual se encuentran las y los sujetos. La identidad es entendida como un conjunto de prácticas (materiales y simbólicas) estructuradas culturalmente y organizadas desde una posición social particular que puede tener como origen la clase, la raza, la etnia, la edad, el sexo y/o una actividad específica, entre otras (MEZA, 2000).

El sistema sexo-género-cuerpo-sexualidad (BUTLER, 2007) determina la construcción de las y los sujetos y las posibilidades que se tienen para insertarse en distintos ámbitos, entre ellos el laboral, y en conjunto con la construcción social del cuerpo del trabajo o productivo establece el empleo en que se pueden insertar.

Figura 1 - Fuente: Elaboración propia.

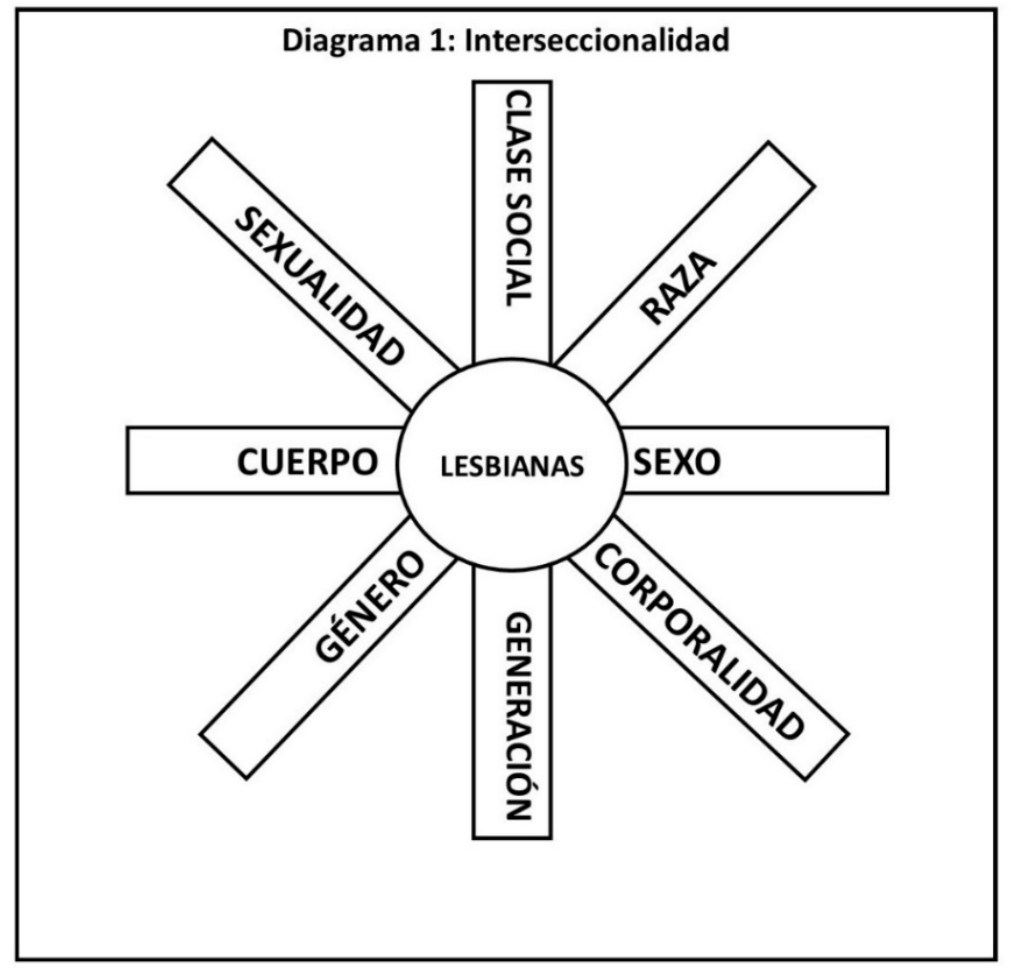




\section{Estudios sobre Lesbianas y Mercado de Trabajo}

Los estudios sobre lesbianas principalmente se centran en la construcción de la identidad, los derechos humanos, discriminación pero en contadas ocasiones han sido abordadas desde la perspectiva laboral y corporal. Tras una ardua búsqueda se encontró una serie de estudios que han abordado de manera general el tema sobre la situación laboral de las lesbianas masculinas y femeninas, aunque poniendo énfasis en diferentes aspecto, tales como las concepciones, actitudes y comportamientos respecto a la discriminación y homofobia en el ámbito laboral (MAIRAL Y PIEDAD, 2009; ADEIM-SIMBIOSIS, ARTEMISA, CATTRACHAS, CRIOLA, IGLHRC Y RED NOSOTRAS, 2006), la relación entre la identidad sexual, heterosexualismo organizacional percibido y las actitudes de trabajo (HERNÁNDEZ, ROVIRA, LUNA, NERIS Y ACEVEDO, 2009), el acoso laboral a miembros de la comunidad LGBTTTIP $^{1}$ (VALENCIA, GUTIÉRREZ Y MAZA, 2011), la experiencia de lesbianas y gays en el trabajo (DI MARCO, ARENAS, MUNDUATE Y HOEL, 2012) y sobre políticas públicas hacia las lesbianas y el ámbito laboral (ALFARACHE, 2009).

En varias de estas investigaciones se realiza un análisis de la violencia, discriminación y exclusión tanto de las lesbianas como de los gays dentro de las ámbitos laborales delimitando su estudio con aquellas lesbianas que cumplen con corporalidades femeninas (MAIRAL Y PIEDAD, 2009; ADEIM-SIMBIOSIS, ARTEMISA, CATTRACHAS, CRIOLA, IGLHRC Y RED NOSOTRAS, 2006; HERNÁNDEZ, ROVIRA, LUNA, NERIS Y ACEVEDO, 2009; DI MARCO, ARENAS, MUNDUATE Y HOEL, 2012), dejando de lado las diferentes formas de trabajo en las que se pueden insertar las lesbianas en base a la construcción social del cuerpo de trabajo que si consideran en su investigación Valencia y Maza (2011), este es uno de los aspectos que se pretende profundizar en este estudio.

Se parte de la hipótesis de que las lesbianas masculinas y femeninas en el estado de Aguascalientes viven en un ambiente laboral de discriminación, violencia y exclusión social por el hecho de tener una sexualidad y/o corporalidad diferente a la establecida. Al ingresar al mercado laboral se comienza a tener una serie de problemas alrededor de la identidad, cuerpo y sexualidad con las y los compañeros de trabajo, jefes/as y clientes. Cuando se comunica la sexualidad o al no cumplir con el sistema sexo-género-cuerpo-sexualidad se propicia un ambiente laboral hostil y enfermizo, ocasionando no solo una baja en la producción, sino, una serie de efectos psicosociales tanto para las lesbianas masculinas y femeninas dentro y fuera de sus áreas de trabajo.

Para las lesbianas femeninas, al sentirse cómodas con su imagen femenina, resulta más fácil acceder a todos aquellos empleos que mediante la construcción social de los cuerpos de trabajo han sido establecidos para la femineidad ya que se cumple con el arquetipo heteronormativo de la 'mujer heterosexual' (valdría la pena discutir respecto a la concepción del ser mujer, pues actualmente podría decirse que este no cubre, ni contempla, la construcción de la mujer no occidental- y podría ser que hasta occidental, por tanto la mujer puede ser desdibujada desde estos parámetros). Sin embargo, no cumple con el estereotipo de lesbianas. La visibilidad de su sexualidad comienza con la verbalización en los espacios laborales generando violencia, discriminación y exclusión hacia ellas, equiparable al que sufren las mujeres heterosexuales, pero 
agravándose al salir del sistema heterosexista y patriarcal.

Las lesbianas masculinas al no sentir comodidad con los códigos de feminidad establecidos y estar en un proceso de performatividad respecto a sus cuerpos y corporalidades, salen de la concepción del ser mujer, sin embargo cumplen con las expectativas que se tienen del 'ser lesbiana'. Al estar expuestas a una construcción social del cuerpo de trabajo $^{2}$ heterosexista y patriarcal que a lo largo de la historia ha establecido una división sexual del trabajo de una manera dicotómica (masculino/femenino), las lesbianas masculina pueden tender a desempeñar trabajos socialmente aceptados para 'hombres', correspondiendo a su corporalidad, invisibilizado su sexualidad y adquiriendo o jugando con una perfomatividad respecto a su sexo, género, sexualidad y cuerpo, permitiéndoles ingresar y permanecer dentro del mercado de trabajo.

\section{Metodología}

Mediante la aplicación de la técnica metodológica la triangulación se desarrolló un análisis mixto. En la parte cuantitativa se analizó la base de datos de la Encuesta Nacional sobre Discriminación en México (ENADIS) del 2010, la Encuesta Nacional de Ocupación (ENOE) y Empleo y la Encuesta Laboral y de Corresponsabilidad Social (ELCOS), mediante la utilización del paquete estadístico SPSS v.18 se trató la información permitiendo obtener una serie de resultados convenientes para la investigación teniendo como principal objetivo conocer la situación $\mathrm{y}$ condiciones laborales de las mujeres lesbianas y no lesbianas en México.

En la parte cualitativa se realizaron tres entrevistas a profundidad a lesbianas que cumplieran con la característica de haber estado insertas en algún empleo y tener una corporalidad masculina, femenina y andrógina; con el fin de poder comprender las estrategias que utilizan y/o han utilizado para poder insertarse, desarrollarse $\mathrm{y}$ reinsertarse en el ámbito laboral., las entrevistas se realizaron el mes de mayo del año 2014 en el municipio de Aguascalientes, México.

A continuación se realiza una descripción de cada una de las sujetas entrevistadas:

Sujeta 1 (femenina): Se denomina lesbiana con una corporalidad femenina $y$ comportamiento masculino tiene actitudes de caballerosidad (abrir la puerta, pagar la cuenta, encender el cigarrillo de la otra persona especialmente si es una mujer, entre otras actitudes). Su edad es de 33 años, es soltera y vive con sus padres; pertenecer a una clase social alta, su nivel de escolaridad terminando es de licenciada y actualmente realiza la maestría. Expresa haber descubierto su sexualidad a los 17 años y ser católica. Su estado civil es soltera y no tiene pareja actualmente.

Sujeta 2 (andrógina): Se reconoce a sí misma como lesbiana de cuerpo femenino, su comportamiento no es completamente femenino ni masculino, tiene actitudes de caballerosidad, sin embargo también tiende a tener actitudes femeninas (juego con las manos, coquetería, sutileza al hablar y una gran carga de sentimentalismo, entre otras). Expresa tener un estado socioeconómico medio-alto, vive independiente de sus padres, su edad es de 35 años, y a pesar de que su estado civil es soltera, se encuentra comprometida con una mujer con un hijo y una hija donde representa el papel del 'hombre' (mantiene la casa, es la enojona, etc.) Descubrió su sexualidad a los 19 años y se dice católica. Su escolaridad es de licenciatura $y$ actualmente se encuentra cursando la maestría.

Sujeta 3 (masculina): Se autodenomina lesbiana masculina en proceso de transformación tras género, mantiene relaciones amorosas, afectivas y eróticas con otras lesbianas de preferencia femeninas. Tiene un cuerpo de mujer (biológicamente) 
pero masculino en su complexión: no tiene casi senos, no depila su cuerpo y sus hombros son anchos. Su comportamiento es masculino, su voz es gruesa, sin embargo no deja de tener algunas actitudes femeninas como algunas posturas en sus manos y ocasiones modulaciones agudas en su voz, o posturas corporales. Prefiere que se le nombre en masculino, su edad es de 26 años, vive independiente de sus padres, es soltera y tiene actualmente una relación. Expresa ser de una clase socioeconómica media, ser católica y haber descubierto su sexualidad a los 15 años. El nivel de escolaridad terminado es de educación media y actualmente cursa una licenciatura.o.

\section{Resultados}

a) Mercado de trabajo y condiciones laborales de las mujeres, lesbianas y no lesbianas

"El mercado laboral es el punto de encuentro entre quienes ofrecen su fuerza de trabajo por un salario y aquellos que la pueden y quisieran comprar" (DE LA GARZA, 2002, p. 1). Se divide en mercado formal el cual teóricamente brinda seguridad de vivienda, salud y salario. La informalidad es concebida como a todos aquellos empleos que no cuentan dentro de la normativa legal y que no brindan seguridad ni prestaciones al salario, la salud y la vivienda.

De la muestra de lesbianas encuestadas del apartado de Minorías Sexuales de la ENADIS (2010) 60\% expresaron contar con un empleo por lo que forman parte de la población económicamente activa (PEA), $40 \%$ restante son económicamente 'no activa'. La proporción de la participación en la producción de bienes y servicios de las lesbianas es dieciocho puntos superior en comparación con las mujeres, de acuerdo con los datos del cuarto trimestre del 2014 de la ENOE, 42.8\% de las mujeres de 14 años y más forman parte de la PEA.

Gráfica 1. Distribución porcentual por ocupación principal de las lesbianas.

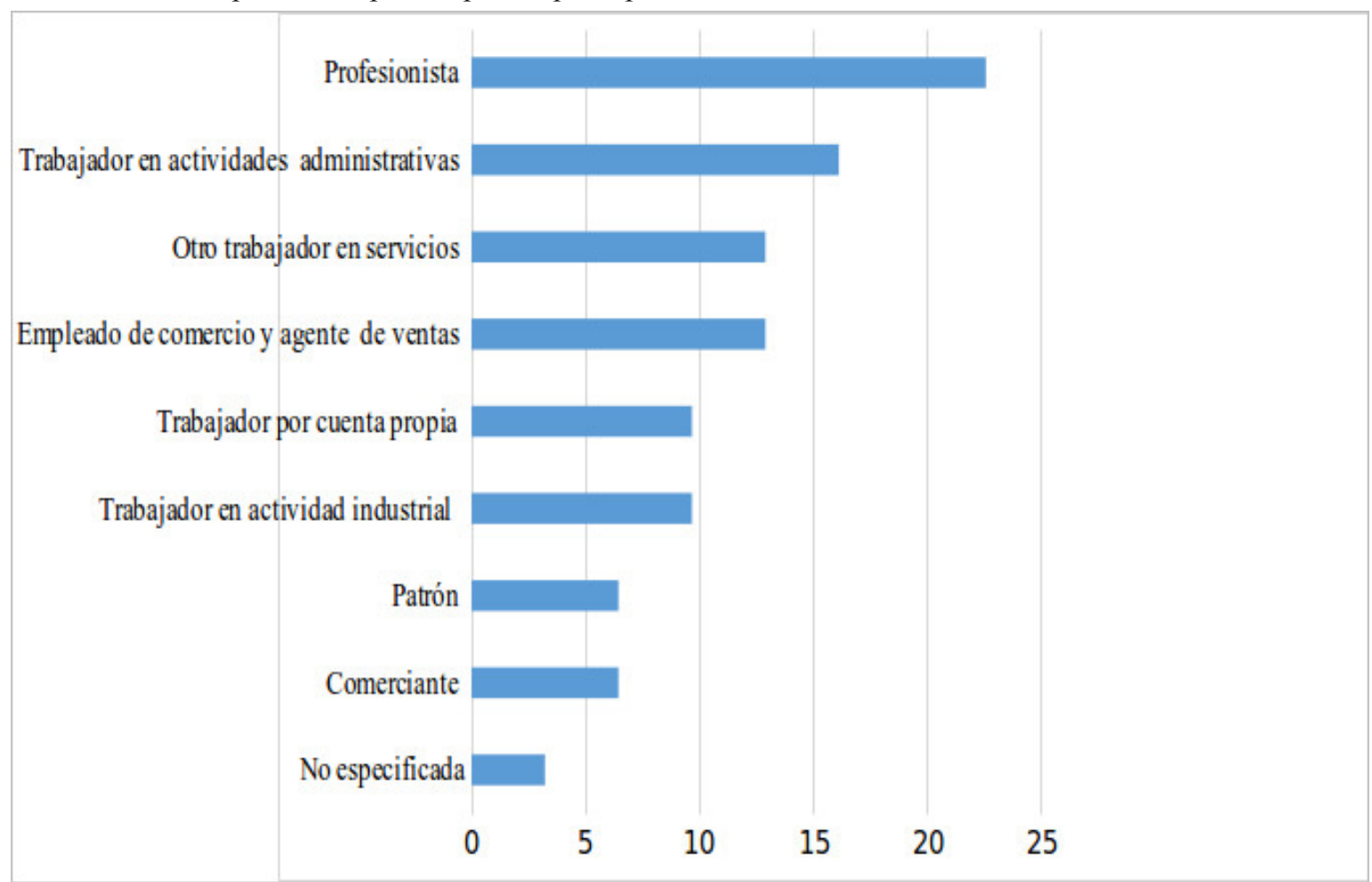

Fuente: Elaboración propia con base en el apartado sobre minorías sexuales de la ENADIS, 2010. 
De las lesbianas económicamente no activas, se dedican al estudio un $47.4 \%$, mientras que $36.8 \%$ trabaja en las labores del hogar. El trabajo doméstico sigue siendo considerado como un 'no trabajo', ya que al no tener una remuneración económica forma parte de las actividades culturalmente obligatorias de las mujeres. De la población no activa económicamente $94.7 \%$ las sostiene un familiar u otra persona, mientras que 5.3\% recibe una pensión por viudez, orfandad o divorcio.

De las lesbianas económicamente activa podemos observar en la gráfica 1 , que $22.6 \%$ se desempeñan como profesionistas, es decir que cuentan con una instrucción a nivel de educación superior o licenciatura, $16.1 \%$ se encuentran insertas como trabajadoras en actividades administrativas, $12.9 \%$ como empleadas de comercios y agentes de ventas $\mathrm{y}$, con el mismo porcentaje se encuentran laborando en el área de los servicios, siendo estas las actividades más representativas de los resultados obtenidos.

Sobre condiciones contractuales, de las lesbianas económicamente activa $67.7 \%$ cuenta con contrato, de las cuales, $76.2 \%$ tiene un contrato escrito, por tanto podría deducirse que se encuentran en la formalidad; y $19.1 \%$ es verbal, es decir que cuentan con un trabajo informal. En comparación con las mujeres ocupadas que sólo $42.8 \%$ cuentan con contrato escrito las lesbianas en mayor proporción se desempeñan en trabajos con ciertas condiciones de formalidad contractual.

De acuerdo con las prestaciones laborales reglamentarias según el marco jurídico e institucional mexicano ${ }^{3}, 19.4 \%$ cuenta con todas las prestaciones de ley, mientras que $90.3 \%$ solo cuenta con un servicio de salud; entre los cuales se encuentra $60.7 \%$ afiliadas al $\mathrm{IMSS}^{4}, 10.7 \%$ al $\mathrm{ISSSTE}^{5}, 25 \%$ cuentan con un servicio de salud privado y $3.6 \%$ tiene servicios médicos de PEMEX. En el caso de las mujeres ocupadas solo $43.3 \%$ cuentan con servicios de salud. En general las lesbianas que desempeñan una actividad económica tienen más prestaciones laborales en comparación con las mujeres (Gráfica 2).

Gráfica 2. Distribución porcentual de las prestaciones laborales de las lesbianas y mujeres activas conómicamente.

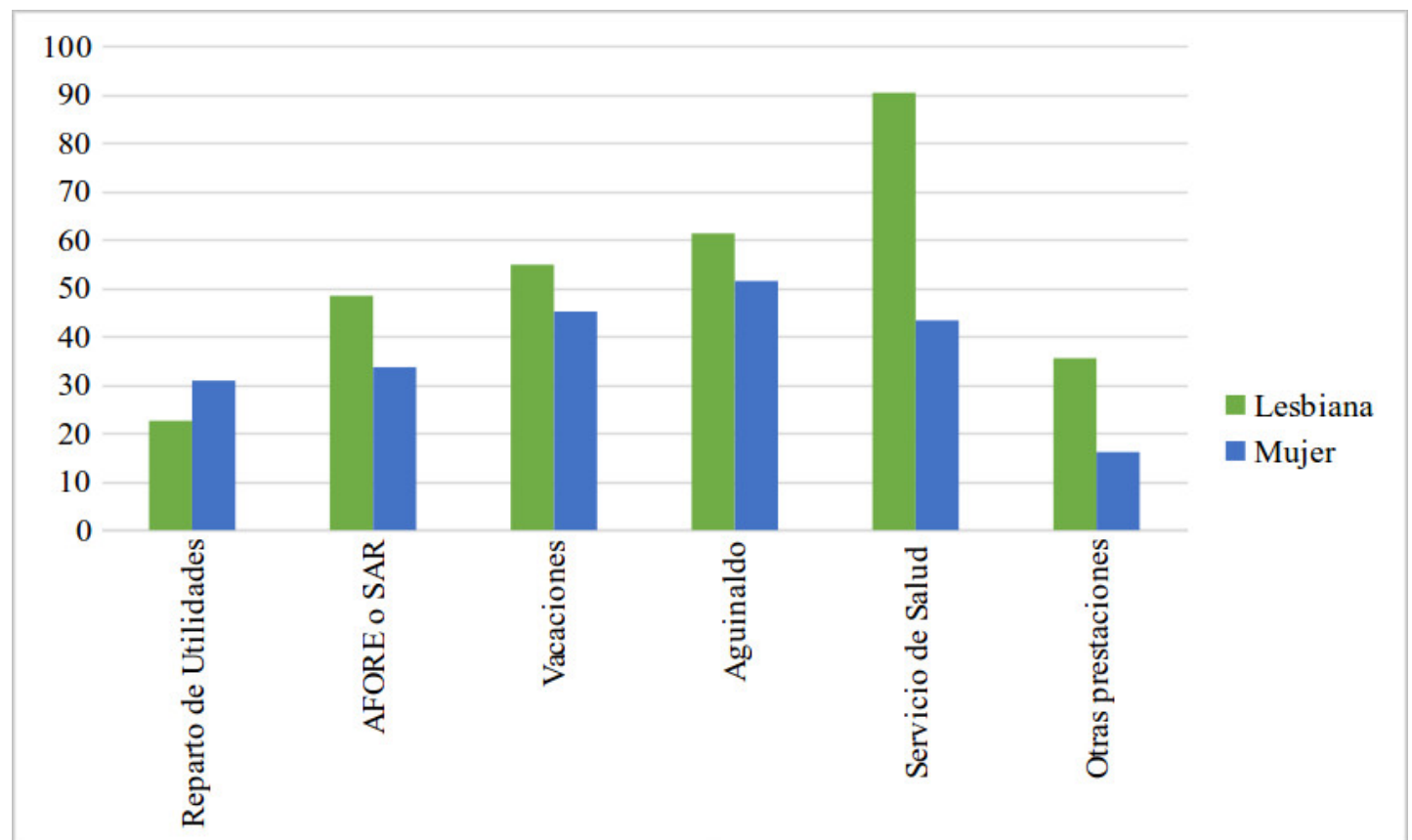

Fuente: Apartado de minorías sexuales de la ENADIS, 2010 y Encuesta Laboral y de Corresponsabilidad Social (ELCOS) 2012. 
De las tres entrevistadas (Tabla 1) solo la Sujeta 1 cuenta con todas las prestaciones, la Sujeta 2 cuenta con aguinaldo, vacaciones pagadas y vales de despensa, pero estas prestaciones son en conjunto de los tres trabajos con los que cuenta y la Sujeta 3 no cuenta con ningún tipo de prestación social en su trabajo.

En el caso de las entrevistadas (Tabla 1) las Sujetas 1 está dentro del sector formal, cuentan con contrato, con todas las prestaciones presentadas en la gráfica $2 \mathrm{y}$ desempeña un puesto de jefatura; la Sujeta 2 se encuentra en el sector formal e informal pues cuenta con contrato en algunos de sus trabajos, pero no en todos tiene todas las prestaciones de ley, actualmente desempeña tres trabajos médico de urgencias, médico clínico y médico laboral; la Sujeta 3 no cuenta con contrato, ni prestaciones por tanto se encuentra en el sector informal, desempeñando un puesto de mesero en un restaurante.

Tabla 1. Condiciones laborales del/los empleos actuales de las entrevistadas.

\begin{tabular}{|c|c|c|c|c|c|c|c|}
\hline $\begin{array}{c}\text { Variable/ } \\
\text { Entrevistadas }\end{array}$ & $\begin{array}{c}\text { Sector } \\
\text { encuentra } \\
\text { inserta }\end{array}$ & $\begin{array}{c}\text { Número de } \\
\text { empleos } \\
\text { actualmente }\end{array}$ & Ocupación & $\begin{array}{l}\text { Puesto que } \\
\text { desempeña }\end{array}$ & $\begin{array}{c}\text { Contrato } \\
\text { escrito }\end{array}$ & $\begin{array}{c}\text { Prestacion } \\
\text { es con las } \\
\text { que } \\
\text { cuenta }\end{array}$ & Antigüiedad \\
\hline Sujeta 1 & Formal & 1 & $\begin{array}{l}\text { Trabaja en } \\
\text { una } \\
\text { empresa de } \\
\text { la industria } \\
\text { privada y } \\
\text { estudia la } \\
\text { Maestría. }\end{array}$ & $\begin{array}{c}\text { Jefatura en } \\
\text { servicio al } \\
\text { clientepriva } \\
\text { da y estudia } \\
\text { la } \\
\text { Maestría }\end{array}$ & $\mathrm{Si}$ & $\begin{array}{l}\text { Seguro de } \\
\text { salud, } \\
\text { aguinaldo, } \\
\text { vacaciones } \\
\text { pagadas, } \\
\text { vivienda, } \\
\text { seguro de } \\
\text { vida, y } \\
\text { vales de } \\
\text { despensare } \\
\text { parto de } \\
\text { utilidades }\end{array}$ & Cinco años \\
\hline Sujeta 2 & Formal & 3 & $\begin{array}{l}\text { Médico y } \\
\text { estudia la } \\
\text { Maestría. }\end{array}$ & $\begin{array}{c}\text { 1. Médico } \\
\text { consultorio } \\
\text { 2. Médico } \\
\text { de urgencia. } \\
\text { 3. Médico } \\
\text { laboral }\end{array}$ & $\mathrm{Si}$ & $\begin{array}{l}\text { Vacaciones } \\
\text { pagadas, } \\
\text { vales de } \\
\text { despensa y } \\
\text { aguinaldo }\end{array}$ & $\begin{array}{l}\text { 1. Un año } 2 . \\
\text { Dos año } 3 . \\
\text { Tres meses }\end{array}$ \\
\hline Sujeta 3 & Informal & 1 & $\begin{array}{l}\text { Estudia y } \\
\text { trabaja de } \\
\text { mesero }\end{array}$ & Mesero & No & No & Dos meses \\
\hline
\end{tabular}

Fuente: Elaboración propia con base en el apartado sobre minorías sexuales de la ENADIS, 2010. 
Por lo que se puede concluir que la situación laboral de las lesbianas es muy favorable ante el panorama en el que se viven las mujeres actualmente en México, ya que una proporción mayor al promedio de las mujeres se encuentran insertas en una actividad económica; un alto porcentaje se encuentran insertas en la formalidad en comparación con el promedio de las trabajadoras mexicanas y a pesar de que no todas cuentan con todas las prestaciones de ley, una quinta han logrado desempeñarse en empleos en los que se encuentran bajo el amparo legal e institucional del trabajo. Por lo tanto han tenido la capacidad de insertarse en el mercado laboral en mejores condiciones que las mujeres en general. Por lo que es preciso cuestionar: ¿Cuáles han sido las estrategias que han utilizado para poder insertarse $y$ reinsertarse en el mercado laboral? ¿Qué costos ha tenido esta inserción en su sexualidad y su cuerpo? ¿Cómo ha afectado su vida fuera y dentro del trabajo la adaptación a las exigencias laborales?

\section{b) Trayectorias laborales de las lesbianas}

Al igual que el cuerpo y la corporalidad, para poder rescatar las experiencias y estrategias que han aplicado las tres sujetas entrevistadas para buscar empleo, insertarse en un trabajo, mantenerse en él y en dado caso volver a buscar y reinsertarse en el mercado laboral; fue necesario aplicar a las entrevistadas un cuestionario especializado sobre 'trayectorias laborales' (Tabla 2), estas reflejan la construcción de las sujetas tocando temas como la escolaridad, el nivel socioeconómico, su corporalidad, redes sociales, capacidad de cumplir al sistema sexo-género-sexualidad-cuerpo.

Tabla 2. Reconstrucción de la trayectoria laboral de las entrevistadas.

\begin{tabular}{|c|c|c|c|}
\hline $\begin{array}{c}\text { Entrevistada/ } \\
\text { Variables }\end{array}$ & Sujeta 1 & Sujeta 2 & Sujeta 3 \\
\hline $\begin{array}{l}\text { Número de empleos } \\
\text { tomando en cuenta el } \\
\text { actual }\end{array}$ & 8 & 16 & 9 \\
\hline $\begin{array}{c}\text { Edad en la que empezó } \\
\text { a laborar }\end{array}$ & 22 años & 16 años & 18 años \\
\hline $\begin{array}{l}\text { Razón por la que } \\
\text { comenzó a trabajar }\end{array}$ & $\begin{array}{c}\text { Terminó de su } \\
\text { carrera universitaria }\end{array}$ & $\begin{array}{l}\text { Necesidad de sentirse } \\
\text { autosuficiente }\end{array}$ & $\begin{array}{c}\text { Terminó la preparatoria y no } \\
\text { ingreso a la Universidad }\end{array}$ \\
\hline $\begin{array}{l}\text { Sectores en los cuales ha } \\
\text { estado inmersa }\end{array}$ & Formal & Formal/Informal & Informal \\
\hline \multirow{8}{*}{$\begin{array}{c}\text { 1. Médico consultorio } 2 . \\
\text { Médico de urgencia. } 3 . \\
\text { Médico laboral }\end{array}$} & D. de proyectos & Ventas & Auxiliar general \\
\hline & Jefaturas & Edecán & Ventas \\
\hline & & Taxista & Mesero \\
\hline & & Paramédico & Lava lozas \\
\hline & & Médico general & \\
\hline & & Médico de turno & \\
\hline & & Médico de urgencias & \\
\hline & & Médico laboral & \\
\hline
\end{tabular}




\begin{tabular}{|c|c|c|c|}
\hline $\begin{array}{l}\text { Dif. para ingresar a } \\
\text { los empleos }\end{array}$ & No & No & No \\
\hline \multirow{2}{*}{$\begin{array}{l}\text { Forma de conseguir } \\
\text { los empleos }\end{array}$} & $\begin{array}{c}\text { Por de amistades de su } \\
\text { padre y amigos. }\end{array}$ & $\begin{array}{l}\text { Recomendaciones de } \\
\text { familiares y amigos. }\end{array}$ & \multirow{2}{*}{$\begin{array}{c}\text { Anuncios en periódico e } \\
\text { internet }\end{array}$} \\
\hline & $\begin{array}{l}\text { Recomendaciones de } \\
\text { anteriores trabajos. }\end{array}$ & $\begin{array}{l}\text { Anuncios en periódico e } \\
\text { internet }\end{array}$ & \\
\hline \multirow{4}{*}{$\begin{array}{l}\text { Motivos de cambio } \\
\text { de empleo }\end{array}$} & $\begin{array}{l}\text { Mejores propuestas de } \\
\text { trabajo. }\end{array}$ & Mejores oferta de trabajo. & Cambio de residencia. \\
\hline & Cambio de domicilio. & Cambio de residencia. & Problemas con los jefes. \\
\hline & $\begin{array}{l}\text { Mal entendido con un } \\
\text { jefe. }\end{array}$ & $\begin{array}{c}\text { Falta de tiempo para } \\
\text { estudiar. }\end{array}$ & Acoso sexual. \\
\hline & & & $\begin{array}{c}\text { Falta de tiempo para } \\
\text { estudiar. }\end{array}$ \\
\hline $\begin{array}{l}\text { Duración en los } \\
\text { empleos (menor y } \\
\text { mayor) }\end{array}$ & $\begin{array}{l}\text { De } 3 \text { meses hasta } 5 \\
\text { años a la actualidad. }\end{array}$ & $\begin{array}{c}\text { En la actualidad tiene de } 3 \\
\text { a } 5 \text { meses en sus empleos y } \\
\text { el de mayor duración } 3 \\
\text { años. }\end{array}$ & $\begin{array}{c}15 \text { días y hasta } 10 \\
\text { meses, en la actualidad } 2 \\
\text { meses }\end{array}$ \\
\hline $\begin{array}{c}\text { Ingreso mensual en } \\
\text { pesos }\end{array}$ & \multirow[t]{2}{*}{$\$ 9000$ a $\$ 37000$} & \multirow[t]{2}{*}{$\$ 8000$ a $\$ 25000$} & \multirow[t]{2}{*}{$\$ 1200$ a $\$ 2400$} \\
\hline (menor y mayor) & & & \\
\hline Tiempo en desempleo & \multirow[t]{2}{*}{$\begin{array}{c}\text { En el único trabajo que } \\
\text { estuvo en desempleo } \\
\text { duro } 9 \text { meses. }\end{array}$} & \multirow[t]{2}{*}{15 días hasta 3 meses. } & \multirow[t]{2}{*}{$\begin{array}{c}15 \text { días hasta } 1 \text { año y } \\
\text { medio }\end{array}$} \\
\hline (menor a mayor & & & \\
\hline
\end{tabular}

Fuente: Elaboración propia.

La trayectoria laboral que presentan las entrevistadas permite observar la capacidad que han tenido para insertarse en diferentes sectores laborales (formal e informal) así como la importancia del nivel socioeconómico, las redes sociales y cumplir con las características necesarias, escolaridad e imagen corporal. La correspondencia sobre su sexo, género y cuerpo y el tipo de trabajo en el que se han desempeñado les ha permitido ocultar su lesbianismo, dándoles la oportunidad de formar parte de la heteronormatividad en el ámbito laboral.

c) Estrategias de supervivencia de las lesbianas femeninas, masculinas $y$ andróginas en el mercado laboral

Sobre la visibilidad en el trabajo las sociólogas Pilar Maira y Luz Piedad (2009) realizan una propuesta sobre la visibilidad e intimidad de los gay y las lesbianas en el 
ámbito laboral; esta última se refiere a la necesidad de ocultar o guardar su sexualidad para sí, ya que la intimidad es una de las características de la profesionalidad y por tanto es necesario no pronunciar u ocultar su sexualidad dentro de la empresa para ser profesional, lo que lleva a discutir la visibilidad, la cual se puede presentar de cuatro formas: negativa (consecuencias negativas al expresarlo dentro del área laboral), tranquilizadora (se cumple con normas y expectativas sociales), intranquilizadora (transgrede pautas sociales donde se presenta una negación de la homosexualidad) y la positiva (fuera del ámbito laboral).

En el caso de la Sujetas 1, 2 y 3 resulta ser negativa pues expresar su sexualidad representa una amenaza dentro del área laboral, correspondiente a la percepción de la intimidad en relación con el profesionalismo:

(...) lo que pasa es que yo creo que vas a trabajar, no vas a conseguir novio, ni novia, ni nada por el estilo, y no lo haría porque yo creo que si podría traer consecuencias negativas. Hoy acepto que no todo el mundo es feliz con la sexualidad de uno, o sea hay gente que tiene prejuicios, es la realidad, entonces por mucho que yo crea conocer a mi jefe y crea conocer a las demás personas, realmente no los conozco como ellos realmente no me conocen, yo sé que nadie me va a despedir o ascender porque soy gay, no, pero al momento de valorar todo el escenario para ver si hay un ascenso o un incremento de salario, podría salir eso a relucir y yo no quisiera que eso fuera un problema para mí en lo laboral (...) (Sujeta 1, Jefatura en empresa del sector privado, 33 años).
En el trabajo realizado por RosarioHernández, Rovira, Luna, Neris y Acevedo (2009) postulan tres tácticas de adaptación en el ámbito laboral: a. Construir o simular una vida e identidad heterosexual; b. Evitar, mantener un distanciamiento social $y$ aparentar ser asexual; c. Mediante una estrategia de adaptación aceptar su sexualidad con las y los compañeros de trabajo.

La Sujeta 1 utiliza la táctica $b$. evita, mantiene un distanciamiento social $y$ aparentando ser asexual. El tener un puesto de jefatura le permite evitar preguntas sobre su sexualidad por parte de sus subordinados y en caso de tener cuestionamientos responde de tal manera que pueda ocultar su sexualidad; busca la manera más sutil y diplomática para terminar con los coqueteos e insinuaciones por parte de sus compañeros hombres (acoso sexual).

(...) eso me ha costado trabajo, porque en cierto punto lo que he hecho es que no conviva con muchos (compañeros) del trabajo, pero también prefiero no hacerlo para evitar broncas por esta gay mía. Había un señor $x$ que me coqueteaba al principio cuando empecé en la empresa, entonces yo siempre le contestaba sus coqueteos con una broma ;Ay x!, o yo quería una silla de las que a él le sobraban en su área, me decía si pero si vienes a sentarte acá conmigo, y cosas así, me iba y me sentaba y ya le decía -ya me estoy sentando contigo, me das mi silla y se reía y ya me daba la silla (...) (Sujeta 1, Jefatura en empresa del sector privado, 33 años).

El distanciamiento social con los compañeros actualmente le ha causado un 
conflicto ya que para poder ascender de puesto es necesario que comience a notarse, asistir a todos los eventos que realice la empresa para que la puedan promover. Dichas reuniones son para pareja heterosexuales en muchas de las ocasiones. La alternativa que ha encontrado es asistir sola, es decir, no simular una vida en pareja heterosexual, antes que pedirle a dos de sus compañeros que son disidentes de la heterosexualidad que la acompañen a esos eventos y de esta manera poder ocultar/disimular su sexualidad.

(...) yo hablé con el gerente de planta que como le podía hacer para crecer, y él me dijo que me vieran, que hablara la gente bien de mí, o sea me dijo entre dientes ve a todos los eventos, yo nunca voy a esos eventos de parejas, tenía 5 años sin ir, (dije) pues voy a tener que ir a este chingado evento, yo estaba preocupada ¿con quién voy a ir de pareja? Entonces estaba pensando voy a tener que llevar algún amigo, pero todos eran más amigas que amigos (homosexuales), entonces dije no, ¿a quién llevo? hasta pensé en decirle a mi hermano menor, ya estaba yo bien conflictuada, cuando dije no voy a ir a llevar a alguien a dar otra imagen, voy a ir yo sola y se acabó, (ellos) saben que no tengo novio entonces para que llevo a alguien (...) que me pregunten, les digo pues a quien traigo, si no hay (Sujeta 1, Jefatura en empresa del sector privado, 33 años).

En el caso de la Sujeta 2 su estrategia es la c. acepta su sexualidad mediante una táctica de adaptación, aceptando su sexualidad con las y los compañeros de trabajo, pero cuando no es conveniente expresar su sexualidad utiliza la $b$. evitando, mantener un distanciamiento social y aparentar ser asexual.

(...) es reciente que lo empiezo a decir (soy lesbiana), cuando tenía mi otra pareja yo decía que era mi amiga, había aprendido a decirles a la gente lo que quería oír, antes me preguntaban es tu hermana, si es mi hermana, es tu prima, si es mi prima, después se conflictuaban, me volvían a preguntar, entonces es tu prima o tu hermana, es mi prima hermana (...) (Sujeta 2, Médico, 35 años).

Actualmente al convivir con sus compañeros/as de trabajo no tiene problemas sobre su sexualidad y puede expresarlo libremente y argumenta que la manera en la que logro que esto sucediera es por medio de la educación constante de las personas.

(...) Ahorita te digo, todo el mundo lo sabe y no hay ningún problema, de hecho voy a ir a una fiesta $y$ esperan que vaya ella (pareja) y no tengo broncas. Yo creo que depende del carácter, en cómo te desenvuelvas con ellos, en cómo se los hagas ver, desde mi punto de vista si uno mismo empieza, es que no quiero que nadie sepa porque me van a hacer esto y esto otro, ya uno solito se está cerrando las puertas y creo que desde ahí tienes que empezar a abrirte a educar a las personas (...) (Sujeta 2, Médico, 35 años).

Sobre la estrategia que utiliza la Sujeta 3 en los primeros tres trabajos corresponde al inciso c) acepta su sexualidad mediante una táctica de adaptación, pero en los siguientes tres trabajos contando el actual ha optado por 
la opción a. construir o simular una vida e identidad heterosexual masculina.

\section{¿Por qué no dijiste que eras lesbiana? \\ (...) ya me había cansado de broncas, de cómo eres, a ver eres mujer, seguro que eres mujer, entonces dije me pongo Diego y ya (Sujeta 3, Mesero, 26 años).}

Tras preguntar a la Sujeta 1 y 3 ¿si tuviera la oportunidad de expresar su sexualidad en la empresa, lo haría? sus respuestas fueron negativas, y argumentan:

Aquí en México es mejor que no lo diga (...), aquí en Aguascalientes no, pero si yo viviera en otro país estoy segura que sería otro rollo, en otro estado, por ejemplo en el DF, en Guadalajara, en Monterrey, en esas tres ciudades si sería abierta, no creo que haya tanto problema, pero aquí en Aguascalientes ni de chiste (broma) porque yo creo que si habría bastante problema (...) (Sujeta 1, Jefatura en empresa del sector privado, 33 años)

No, no lo expresaría, porque les conflictuaría, pues, en todos lados es conflictivo, porque me vez físicamente y digo, me vez y piensas es un bato (hombre) cualquiera y no soy mujer, como que si se sacan de onda (...) (Sujeta 3, Mesero, 26 años)

En el caso de la Sujeta 2 asegura que cuando tiene la oportunidad de expresarlo, lo hace:

(...) a veces yo prefiero, primero tantear el terreno, y ya después decido decirlo abiertamente, yo siempre he tenido un lema que es que a mí ya me costó bastante aceptarlo, que les cueste el mismo trabajo aceptarlos a ellos, que me quieran como soy y el que no pues no, más a gusto estábamos (...) (Sujeta 2, Médico, 35 años).

\section{Conclusiones}

1. Las condiciones laborales en las cuales se encuentran inmersas las lesbianas femeninas, andróginas y masculinas, es mucho más favorable que el que vive la media nacional en México. Presentando porcentajes que denotan estabilidad a pesar de las condiciones tan cambiantes y las reformas que se han tenido en los últimos años en el mercado laboral nacional;

2. Se encontró que las principales estrategias que emplean las entrevistadas, con base en la propuestas por Rosario-Hernández, Rovira, Luna, Neris y Acevedo (2009), consisten en ocultar/ disimular su sexualidad, pero no solo eso, su sexo-género-cuerpo están condicionados a la oferta laboral que presenta el mercado de trabajo, por lo que tienen que adaptar y en ocasiones fingir otra sexualidad o aparentar tener una vida heterosexual, dejando a un lado su sexualidad, impactando de una manera negativa en los diferentes campos de su desarrollo personal. El simple hecho de no poder expresar su sexualidad libremente para conservar o poder ascender en un empleo es un acto de discriminación en el mercado laboral;

3. La visibilidad en el área laboral es negativa y guarda una elación con el profesionalismo, pues podría pensarse que el expresar su sexo-género-sexualidad-cuerpo implica una connotación sexual, siendo presas de los estigmas dentro del ambiente laboral en el cual se desenvuelven. Por lo 
tanto, no solo deben evitar pronunciar su sexualidad, sino, que deben adaptar su género y corporalidad para pasar lo más desapercibidas posibles y así conservar su empleo;

4. La necesidad de ocultar su sexualidad y heteronormatizar sus cuerpos las ha llevado a tener que ocultar sus vidas dentro del área laboral, e incluso tener que construir realidades ficticias para poder integrarse en la dinámica social de las diferentes áreas laborales en las cuales se insertan; evitar la convivencia con sus compañeras/os y jefes/as, orillándolas en el mejor de los casos a crear una solidaridad o complicidad con otros disidentes de la heterosexualidad. Creando un ambiente de discriminación, aislamiento, violencia y exclusión;

5. Contrario a las hipótesis plateadas en la investigación las lesbianas masculinas al igual que las lesbianas femeninas realizan una performatividad de su cuerpo para poder cumplir con los arquetipos masculinos y femeninos, como una estrategia para poder ingresar al mercado laboral, ya que su oportunidad depender en gran medida en la capacidad de imitar o igualar el comportamiento de la heterosexualidad y el ocultamiento de su lesbianismo;

6. El problema no radica en la capacidad de las personas para trasformar su cuerpo e insertarse en los distintos ámbitos laborales, sino en la incapacidad del mercado laboral de transformar las estructuras para permitir la inserción de todas las personas diferentes en el sistema.

1 Se refiere a la población Lésbico, Gay, Bisexual, Transexual, Travesti, Transgénero e Intersexual.

2 En el sentido en que lo explica Marx en El capital (1867) en donde realiza un análisis de la situación corporal del hombre en las relaciones de trabajo.

3 De acuerdo a la Ley Federal del Trabajo, las prestaciones laborales incluyen seguro médico, vacaciones, aguinaldo, capacitación, vales de despensa, seguro de gastos médicos mayores, fondo de ahorro y bonos de productividad.

4 IMSS se refiere al Sistema Mexicano de Seguridad Social.

$5 \quad$ Instituto de Seguridad y Servicios Sociales de los Trabajadores del Estado.

\section{Referencias}

ADEIM-SIMBIOSIS,

Artemisa; CATTRACHAS, Criola; IGLHRC y RED NOSOTRAS. La Invisibilidad aseguraba el puchero. Lesbianas y discriminación laboral en Colombia, Bolivia, Brasil, Honduras y México. Buenos Aires: Comisión Internacional de Derechos Humanos para Gays y Lesbianas, 2006.

ALFARACHE, Angela. Análisis de la invisibilidad en las políticas públicas hacia las lesbianas en México. México, D.F: CONAPRED. 2009.

BUTLER, Judith. El género en disputa: El feminismo y la subversión de la identidad. España: Ediciones Paidós Ibérica S.A. 2007.

CASTAÑEDA, Ricardo. El cuerpo productivo y sus efectos sobre la motricidad. Revista Educación física y deporte, v. 2, n. 27, p. $11-23,2008$.

DE LA GARZA, Enrique. La flexibilidad del trabajo en México. (Una nueva síntesis). En: GARCÍA GUZMÁN, Brigida (Coord.). Población y Sociedad al Inicio del Siglo XXI. México, D.F.: El Colegio de México, 2002. 
DI MARCO, Donatella; ARENAS, Alicia; MUNDUATE, Lourdes y HOEL, Helge. Experiencia de Lesbianas y Gays en el trabajo. España: Universidad de Sevilla, 2012.

ENADIS. Encuesta nacional sobre discriminación en México. En: MONTENEGRO, Patricia; SAAVEDRA, Alicia (Eds.) Resultado sobre diversidad sexual. Parte 1 percepción $y$ actitudes sobre la igualdad y la tolerancia. México, D.F.: CONAPRED, 2010, p. 17 - 45.

FIOCCHETO, Rossana. La amante celeste: la destrucción científica de las lesbianas. Madrid: Ed. Horas y Horas, 1993.

GIL HERNÁNDEZ, Franklin. Estado y procesos políticos: Sexualidad e interseccionalidad. En: EL DIÁLOGO LATINOAMERICANO SOBRE SEXUALIDAD Y GEOPOLÍTICA, Río de Janeiro, 2009.

ROSARIO-HERNÁNDEZ, Ernesto; ROVIRA, Lillian; LUNA, Carlos; NERIS, Miguel; ACEVEDO, Gustavo. Saliendo del clóset en el trabajo: La relación entre el manejo de la identidad sexual, heterosexismo organizacional percibido, actitudes de trabajo y bienestar psicológico. Revista Puertorriqueña de Psicología, v. 20, p. 103143, 2009.

MAIRAL, Pilar; PIEDAD, Luz. Estudio: Concepciones, actitudes y comportamientos respecto a la homofobia en el ámbito laboral de Coslada. España: Federación Estatal de Lesbianas, Gays,
Transexuales y Bisexuales, 2009.

MEZA, Consuelo. La utopía feminista. Quehacer literario de cuatro narradoras mexicanas contemporáneas. En: MEZA, Consuelo (Eds.) Capítulo II la construcción de la identidad femenina Aguascalientes. Aguascalientes: UAA, 2000, p. 61-89.

VALENCIA, Grecia; BERDEJA, Luis; MAZA, Octavio. Aguascalientes el acoso laboral a miembros de la comunidad LGBTTTIP. En: I CONGRESO IBEROAMERICANO SOBRE ACOSO PSICOLÓGICO LABORAL E INSTITUCIONAL. México, D.F., 2011.
Recebido em 26 de maio de 2015. Aceito em 25 de setembro de 2015. 